\title{
CARACTERIZAÇÃO MORFOAGRONÔMICA E FÍSICO-QUÍMICA DE GERMOPLASMA DE CITRUS
}

\author{
Raiane Mariani Santos ${ }^{1}$, Fernanda Vargas Valadares ${ }^{1}$, Adriana Azevedo Vimercati \\ Pirovani $^{1}$, Daniela Fosse Valbão Venancioํ, Monique Moreira Moulin² \\ ${ }^{1}$ Graduadas em Licenciatura em Ciências Biológicas do Instituto Federal do Estado \\ do Espírito Santo-Ifes Campus de Alegre (nanizinhams@hotmail.com) Espírito \\ Santo-Brasil. \\ ${ }^{2}$ Profa Doutora do Instituto Federal do Estado do Espírito Santo-Ifes Campus de \\ Alegre, Espírito Santo-Brasil.
}

Recebido em: 08/04/2016 - Aprovado em: 30/05/2016 - Publicado em: 20/06/2016
DOI: 10.18677/Enciclopedia Biosfera 2016 124

\begin{abstract}
RESUMO
O gênero Citrus é bastante diversificado, e possui grande importância nutricional e econômica. É a partir da avaliação da diversidade de acessos de citros que se obtém o potencial de uso das variedades para programas de melhoramento e posterior recomendação aos produtores rurais. Neste contexto, o objetivo deste trabalho foi caracterizar e estimar a diversidade das variedades de citros coletadas no Setor de Culturas Permanentes do Ifes Campus de Alegre com base em descritores morfoagronômicos e em descritores físico-químicos. Foram utilizados 24 descritores morfoagronômicos, sendo quinze qualitativos multicategóricos, ou seja, avaliados em classes disponíveis em descritores para Citrus, e nove quantitativos. Para a avaliação das características físico-químicas foram realizadas as seguintes determinações: $\mathrm{pH}$, acidez total titulável, sólidos solúveis totais, umidade e teor de cinzas. Foi observada alta variabilidade fenotípica entre as variedades coletadas, com diferentes formatos, tamanhos e cores de frutos. A caracterização morfoagronômica e físico-química foram eficientes para evidenciar divergência entre os genótipos, sendo importante ferramenta para o conhecimento e uso das variedades de citros. As características quantitativas mensuradas possibilitaram um melhor agrupamento das variedades de citros do Ifes Campus de Alegre, havendo separação satisfatória das laranjas, limões e tangerina.
\end{abstract}

PALAVRAS-CHAVE: análise bromatológica; diversidade fenotípica; recursos genéticos.

\section{CHARACTERIZATION MORPHOAGRONOMIC AND PHYSICAL CHEMISTRY OF CITRUS GERMPLASM}

\footnotetext{
ABSTRACT

The genus Citrus is very diverse, and its nutritional and economic properties are very important. Based on the evaluation of the genetic diversity of Citrus accessions is possible to obtain the potential use of varieties for improvement programs and subsequent recommendation to farmers. In this context, the aim of this study is to characterize and estimate the genetic diversity of Citrus varieties collected in the Permanent Culture Sector at IFES Campus Alegre, based on morphological ENCICLOPÉDIA BIOSFERA, Centro Científico Conhecer - Goiânia, v.13 n.23; p.1398 2016
} 
descriptors and physicochemical descriptors. Twenty-four morphological descriptors were used, fifteen multi-categorical qualitative and nine quantitative. For the evaluation of the physicochemical characteristics, were performed the following determinations: $\mathrm{pH}$, titratable acidity, soluble solids, moisture and ash content. It was observed high phenotypical variability among the varieties collected for both the morphological characteristics and for the bromatological. The morphoagronomic and physicochemical characterization were efficient to estimate the genetic diversity among varieties, showing bullish divergence, and important for the knowledge and use of the varieties of Citrus. Moreover, as the morphological attributes and physicochemical studies were obtained important information for product acceptance by the market.

KEYWORDS: chemical analysis, phenotypic diversity, genetic resources.

\section{INTRODUÇÃO}

A citricultura é um importante ramo da agricultura que engloba o cultivo das laranjas, tangerinas, limões, limas-ácidas, limas-doces, pomelo, cidra, laranja azeda e toranjas. A importância da citricultura vai além da geração de divisas para a economia brasileira, tendo grandes impactos na criação de empregos, na formação de capital, na geração de renda, na agregação de valor e, também, no desenvolvimento regional (ZULIAN et al., 2013).

Vários fatores têm contribuído para o aumento da área plantada no Brasil, entre os quais as condições edafoclimáticas favoráveis para a citricultura, o estabelecimento de indústrias para o processamento de frutos visando à produção de suco concentrado congelado, preços remunerados alcançados pelos produtores e também o potencial de crescimento dos mercados interno e externo (MEDEIROS et al., 2013).

No Brasil, a produção de laranjas merece destaque, com uma produtividade média de 716 caixas por hectare, sendo o maior produtor mundial da cultura (FUNDECITRUS, 2015). O potencial de uso de citros vai além das formas convencionais, onde predomina o consumo de fruta fresca e de suco, abrangendo também outros produtos, como matérias-primas para medicamentos, fragrâncias e sabores, que são utilizados por variadas indústrias na composição de perfumes, fármacos, cosméticos, entre outros que possibilitam a abertura de novos nichos de mercado (ARAÚJO \& SALIBE, 2002).

Para um estudo da diversidade genética é importante uma análise das características morfoagronômicas e físico-químicas. NEGREIROS et al. (2014) ressalta que é a partir da avaliação da diversidade genética de acessos de citros que se obtém o potencial de uso das variedades para programas de melhoramento e posterior indicação aos produtores rurais. O melhoramento de citros visa, principalmente, a obtenção de variedades de copa que apresentem alta produtividade, frutos com poucas sementes, elevado teor de suco, bem como equilíbrio entre teores de açúcares e acidez (SCHWARZ, 2011).

A caracterização e a avaliação visam descrever os diversos acessos de uma coleção de germoplasma, por meio de características de interesse, tais como: produtividade, massa de frutos, espessura de polpa, número de sementes por fruto, aspectos nutricionais do fruto, resistência a pragas e doenças, entre outras, com posterior seleção das plantas com características desejáveis e que se adaptem aos sistemas de produção utilizados pelos citricultores (TODISCO et al., 2012). Neste contexto, o objetivo deste trabalho foi caracterizar e estimar a diversidade das 
variedades de citros coletadas no Setor de Culturas Permanentes do Ifes Campus de Alegre com base em descritores morfoagronômicos e físico-químicos.

\section{MATERIAL E MÉTODOS}

As variedades de citros foram identificadas e coletadas no Setor de Culturas Permanentes do Instituto Federal do Espírito Santo (Ifes), Campus de Alegre, do período de junho a agosto de 2015. O Setor de Culturas Permanentes fica localizado no município de Alegre, ES, Brasil, nas coordenadas geográficas de $20^{\circ} 45^{\prime} 30^{\prime \prime} \mathrm{S}$ e de 4127' 23" W (sistema de referência SIRGAS 2000), compreendendo uma área de seis hectares. O clima da região, segundo classificação de Köeppen, é do tipo "Aw", com estação seca no inverno; temperatura anual média de $23^{\circ} \mathrm{C}$ e precipitação anual em torno de $1.300 \mathrm{~mm}$ (LIMA et al., 2008).

Foram analisadas dez variedades, a saber: laranja 'Bahia', Iaranja 'Seleta', laranja 'Seleta Sanguínea', laranja 'Pêra Rio', laranja 'Pêra Mel', laranja 'Lima', laranja 'Natal Folha Murcha', limão 'Taiti', limão 'Branco' e tangerina 'Ponkan'. As laranjas pertencem à espécie Citrus sinensis, e são caracterizada por maior tamanho do fruto, em geral, de 46 a 72 mm. A laranja 'Bahia', 'Seleta' e 'Seleta Sanguínea' são pouco ácidas, têm polpa suculenta e casca amarelo-clara, sendo que a laranja 'Bahia' não possui sementes e é mais fácil de descascar. As laranjas 'Pêra Rio' e 'Pêra Mel' tem um sabor levemente doce, sendo as mais comercializadas no mercado. A laranja 'Lima' possui sabor suave e doce e é menos ácida que as demais e a laranja 'Natal Folha Murcha' também é pouco ácida, mas de porte maior que a 'Lima'. O limão pertence á espécie $C$. limon, caracterizados por frutos de menor tamanho, em geral, de 27 a $60 \mathrm{~mm}$. O limão 'Taiti' apresenta fruto robusto, polpa esbranquiçada, muito suculenta e de qualidade menos ácida. Já o limão 'Branco' possui um fruto pequeno e muito suculento e um suco de sabor muito ácido. Já a tangerina, pertencente à espécie $C$. deliciosa, possui tamanhos similares às laranjas, mas epicarpos mais espessos (FAGUNDES \& YAMANISHI, 2005).

As caracterizações morfoagronômicas foram efetuadas em plantas de mesma idade, cerca de três anos e selecionadas aleatoriamente para que houvesse maior confiabilidade nos dados obtidos. Foram avaliadas 10 variedades com seis repetições para cada descritor totalizando 60 plantas. As variedades foram caracterizadas por descritores morfoagronômicos essenciais específicos para 0 gênero Citrus, altamente discriminantes, que estão disponíveis em International Board for Plant Genetic Resources (IBPGR, 1988). Foram utilizados 24 descritores, a saber analisados de acordo com escala de notas:

Forma da árvore: (1) elipsoide; (2) esferoide; (3) Obloide.

Hábito de crescimento da planta: (1) ereto; (2) espalhado; (3) inclinado; (4) outro.

Superfície do tronco: (1) liso; (2) sulcado e estriado.

Ciclo de vida vegetativo: (1) sempre viva; (2) decídua; (3) semi persistente.

Divisão da folha: (1) simples; (2) bifoliadas; (3) trifoliadas; (4) pentafoliada; (5) outros.

Ápice da folha: (1) atenuado; (2) acuminado; (3) agudo; (4) obtuso; (5) arredondado; (6) emarginado; (7) outros.

Anexo da lâmina da folha: (1) Séssil (pecíolo ausente); (2) Curto (pecíolo mais curto que a lâmina da folha); (3) Longo (pecíolo mais longo que a lâmina da folha).

Intensidade da cor verde da lâmina- Foi analisado de acordo com uma escala de notas: (1) Clara; (2) Média; (3) Escura. 
Formato da lâmina da folha: (1) Elíptico; (2) Ovalado; (3) Obovado; (4) Lanceolado; (5) Esférico (6) Cordata; (7) Outra.

Margem da lâmina da folha: (1) Crenada; (2) Dentada; (3) Inteira; (4) Sinuada; (5) Outra.

Comprimento da folha - Mensurado com o paquímetro digital calibrado em $\mathrm{mm}$.

Largura da folha - Mensurado com o paquímetro digital calibrado em $\mathrm{mm}$.

Relação comprimento/ largura- Calculado a partir das variáveis acima citadas.

Espessura da folha - Mensurado com o paquímetro calibrado em $\mathrm{mm}$.

Forma da fruta: (1) Esferoide; (2) Elipsoide; (3) Piriforme; (4) Obliqua (assimétrica); (5) Obloide; (6) Ovoide; (7) Outra.

Formato da base da fruta: (1) Pescoço; (2) Convexa; (3) Truncada; (4) Côncava; (5) Côncava com colarinho; (6) Colarinho com pescoço; (7) Outra.

Formato do ápice da fruta: (1) Reniforme; (2) Agudo; (3) Arredondado; (4) Truncado; (5) Depressivo; (7) Outra.

Cor da casca: (1) Verde; (2) Verde-amarelado; (3) Amarelo claro; (4) Amarelo; (5) Amarelo escuro; (6) Laranja claro; (7) Laranja; (8) Laranja Escuro; (9) Rosaamarelo; (10) Rosa-alaranjado; (11) Vermelho; (12) Vermelho-alaranjado; (13) Outra.

Peso da fruta - Foi mensurado em uma balança de precisão.

Comprimento do fruto - Mensurado utilizando paquímetro digital calibrado em $\mathrm{mm}$.

Largura do fruto - Mensurado utilizando paquímetro digital calibrado em $\mathrm{mm}$.

Largura do epicarpo na área equatorial - Mensurado utilizando paquímetro digital calibrado em $\mathrm{mm}$.

Espessura da casca da fruta (mesocarpo) - Mensurado utilizando paquímetro digital calibrado em $\mathrm{mm}$.

Cor da polpa: (1) Branca; (2) Verde; (3) Amarela; (4) Laranja; (5) Rosa; (6) Vermelho claro; (7) Laranja-avermelhada; (8) Vermelho; (9) Roxo.

Para a avaliação das características físico-químicas, foram coletados seis frutos por variedade, sendo armazenados em temperatura de congelamento $\left(-18^{\circ} \mathrm{C}\right)$ no Laboratório de Química Aplicada do Ifes, Campus de Alegre. Para a análise foram utilizados frutos completamente maduros e firmes, conforme estado fisiológico do fruto proposto por CHITARRA \& CHITARRA (2005). As seguintes determinações foram realizadas: $\mathrm{pH}$, acidez total titulável, sólidos solúveis totais, umidade e teor de cinzas, de acordo com as instruções estabelecidas pelas metodologias oficiais do Instituto Adolfo Lutz (IAL, 1985), a saber:

$\mathrm{O} \mathrm{pH}$ dos frutos foi determinado utilizando-se um peagâmetro da marca MS Tecnopon. Para a determinação da acidez total titulável foi realizada a titulação da amostra com solução de $\mathrm{NaOH}$ (Hidróxido de Sódio) a $0,1 \mathrm{M}$. Os sólidos solúveis totais foram determinados por refratometria, em refratômetro digital de mão e expressos em Brix. Para esta avaliação, o fruto foi espremido num espremedor elétrico, e adicionou-se de uma a duas gotas no refratômetro para leitura. Para a determinação da umidade foi utilizado o método gravimétrico com emprego de calor, com o auxílio de uma estufa regulada a $105^{\circ} \mathrm{C}$. A det erminação do teor de cinzas se deu pela incineração da amostra em mufla a $550^{\circ} \mathrm{C}$, a té obtenção de cinzas claras.

A análise estatística das características morfoagronômicas e físico-químicas foram realizadas com auxílio do programa Genes (CRUZ, 2008). A estimativa da matriz de distância por meio das variáveis qualitativas e quantitativas foi obtida com base na distância de Mahalanobis, utilizada pois proporciona correlações entre as variáveis estudadas, além de ser muito utilizada em análises de agrupamentos. $\mathrm{O}$ 
agrupamento dos acessos foi obtido pelo método Unweighted Paired Group Methodusing Arithmetic averages (UPGMA) (DAWYNDT et al., 2006).

\section{RESULTADOS E DISCUSSÕES}

Foi observada alta variabilidade fenotípica entre as variedades coletadas, com diferentes formatos, tamanhos e cores, o que evidencia a diversidade entre as variedades de citros mantidas no Ifes Campus de Alegre. Quanto ao descritor formato da copa da planta, 70\% possuem formato esferoide (tangerina 'Ponkan', limão 'Taiti', limão 'Branco', laranja 'Lima', 'Bahia', 'Seleta 'Comum', 'Seleta Sanguínea') 10\% elipsoide (laranja 'Natal Folha Murcha') e 20\% obloide (laranja 'Pêra Mel' e 'Pêra Rio').

Para os descritores superfície do tronco e hábito de crescimento não houve diversidade fenotípica, todas as variedades apresentaram tronco sulcado e estriado e hábito de crescimento espalhado. Quanto às características foliares foi verificado que o ciclo de vida vegetativo das folhas são sempre-vivas, divisão da folha simples, ápice obovado e anexo da lâmina da folha com pecíolo mais curto. Segundo SARTORI (2012) o gênero Citrus é caracterizado predominantemente por possuir ápice obovado e folhas com pecíolo curto.

Para intensidade da cor da folha foi observada coloração verde médio para $40 \%$ dos acessos (tangerina 'Ponkan', 'Seleta Comum', Iaranja 'Lima', 'Natal Folha Murcha'), as demais apresentaram coloração verde escura. Quanto ao formato da lâmina da folha $90 \%$ foi considerado ovalado (laranja 'Lima', 'Bahia', 'Seleta Comum', 'Pêra Mel', 'Pêra Rio', tangerina 'Ponkan', limão 'Branco' e limão 'Taiti') e $10 \%$ lanceolado ('Natal Folha Murcha'). Resultados similares foram obtidos por LEMOS et al. (2012), para o formato da folha ovalado.

Quanto à margem da lâmina da folha $40 \%$ apresentaram margem crenada (laranja 'Lima', 'Pêra Rio', laranja 'Bahia' e tangerina 'Ponkan') 30\% possuíam margem inteira (laranja 'Pêra Mel', 'Seleta Comum', e 'Natal Folha Murcha') e 20\% apresentou margem dentada (limão 'Taiti' e limão 'Branco'). STENZEL (2011) também encontraram margem inteira para a variedade de laranja 'Natal Folha Murcha'. Para os descritores quantitativos de folha foram obtidas variações bastante discrepantes entre o mínimo e máximo, o que demonstra a alta variabilidade para as variedades analisadas. As médias das variáveis quantitativas morfoagronômicas de folhas encontram-se disponíveis na Tabela 1.

TABELA 1 - Médias das variáveis morfoagronômicas de folhas de citros coletadas no Setor de Culturas Permanentes do Ifes Campus de Alegre.

\begin{tabular}{ccccc}
\hline Variedades & $\begin{array}{c}\text { Comprimento } \\
\text { da folha }\end{array}$ & $\begin{array}{c}\text { Largura da } \\
\text { folha }\end{array}$ & $\begin{array}{c}\text { Relação } \\
\text { comp/larg }\end{array}$ & $\begin{array}{c}\text { Espessura } \\
\text { da folha }\end{array}$ \\
\hline Tangerina 'Ponkan' & $62,09 \pm 1,01$ & $31,59 \pm 0,92$ & $1,98 \pm 0,51$ & $0,18 \pm 0,22$ \\
Limão 'Taiti' & $101,66 \pm 1,03$ & $61,53 \pm 1,01$ & $1,66 \pm 0,36$ & $0,31 \pm 0,53$ \\
Limão 'Branco' & $70,42 \pm 1,06$ & $39,41 \pm 0,84$ & $1,80 \pm 0,92$ & $0,25 \pm 0,26$ \\
Laranja 'Lima' & $69,58 \pm 1,07$ & $36,67 \pm 1,01$ & $1,92 \pm 0,81$ & $0,28 \pm 0,40$ \\
Laranja 'Bahia' & $97,69 \pm 1,09$ & $48,74 \pm 1,09$ & $1,61 \pm 0,55$ & $0,25 \pm 0,31$ \\
'Seleta Comum' & $95,12 \pm 1,10$ & $47,99 \pm 0,90$ & $1,78 \pm 0,63$ & $0,20 \pm 0,54$ \\
'Seleta Sanguínea' & $91,15 \pm 1,08$ & $53,00 \pm 1,02$ & $1,73 \pm 0,81$ & $0,21 \pm 0,42$ \\
'Natal Folha Murcha' & $66,85 \pm 1,01$ & $39,67 \pm 1,30$ & $1,69 \pm 0,91$ & $0,27 \pm 0,36$ \\
'Pêra Mel' & $76,50 \pm 1,07$ & $40,70 \pm 0,85$ & $1,88 \pm 0,70$ & $0,26 \pm 0,44$ \\
'Pêra Rio' & $78,59 \pm 1,30$ & $44,57 \pm 1,03$ & $1,78 \pm 0,90$ & $0,25 \pm 0,33$ \\
\hline
\end{tabular}

Para o comprimento e a largura da lâmina foliar $(\mathrm{mm})$ houve grande diversidade fenotípica. O comprimento variou de 62,09mm (tangerina 'Ponkan') a ENCICLOPÉDIA BIOSFERA, Centro Científico Conhecer - Goiânia, v.13 n.23; p.1402 2016 
101,66mm (limão 'Taiti') e a largura variou de 31,59mm (tangerina 'Ponkan') $61,53 \mathrm{~mm}$ (limão 'Taiti'). PIMENTEL et al. (2013) encontraram uma variação de $63 \mathrm{~mm}$ a $104 \mathrm{~mm}$ para o comprimento da lâmina foliar, muito similar ao encontrado neste estudo.

A relação comprimento/largura da lâmina foliar variou de 1,61mm (laranja 'Bahia') a 1,98 mm (tangerina 'Ponkan'). A característica espessura da folha teve uma variação média de $0,18 \mathrm{~mm}$ a $0,31 \mathrm{~mm}$, sendo a tangerina 'Ponkan' a de menor espessura e o limão 'Taiti' de maior espessura.

Quanto ao formato da fruta, $10 \%$ apresentaram formato piriforme (tangerina 'Ponkan'), 10\% obloide (laranja 'Seleta Sanguínea'), 10\% obliqua (laranja 'Natal Folha Murcha'), 20\% elipsoide (laranja 'Lima' e 'Seleta Comum'), 50\% esferoide (limão 'Branco' e 'Taiti', laranja 'Bahia', 'Pêra mel', 'Pêra Rio').Oliveira et al. (2008) ao estudarem a laranja 'Lima' também encontraram o formato elipsoide e Paiva \& Oliveira (2006) para a laranja 'Bahia' encontraram formato esferoide.

Para o descritor base da fruta, 10\% apresentaram base com pescoço (tangerina 'Ponkan'), 40\% base convexa (limão 'Taiti', limão 'Branco', laranja 'Pêra Rio', 'Natal Folha Murcha') e 50\% base truncada (laranja 'Lima', 'Bahia', 'Seleta Comum', 'Seleta Sanguínea' e 'Pêra Mel'). TODISCO et al. (2012) encontraram resultados similares para as variedades de base convexa.

Com relação ao ápice da fruta, $10 \%$ apresentaram formato do ápice depressivo (tangerina 'Ponkan'), 20\% ápice reniforme (limão 'Taiti' e 'Branco'), 40\% ápice truncado (laranja 'Lima', 'Bahia', 'Seleta Sanguínea' e 'Pêra Mel') e 30\% ápice arredondado ('Natal Folha Murcha', 'Pêra Rio' e 'Seleta Comum').

A característica cor da casca (epicarpo) foi a que apresentou maior diversidade fenotípica de uma variedade para outra. A tangerina 'Ponkan' apresentou a coloração laranja entre os acessos avaliados. TODISCO et al. (2012), em suas pesquisas também obtiveram a coloração laranja para as tangerinas, inclusive a 'Ponkan'. O limão 'Taiti' e o limão 'Branco' apresentaram a coloração verde, segundo os padrões do PROGRAMA BRASILEIRO PARA MODERNIZAÇÃO DA HORTICULTURA (2013) essa é a cor ideal para o mercado consumidor.

Os acessos de laranja 'Lima', 'Bahia', 'Seleta Comum' e 'Seleta Sanguínea' apresentaram a coloração amarela. E os acessos de 'Pera Mel', 'Pera Rio', 'Natal Folha Murcha' apresentaram a coloração verde-amarelada.

A variável textura da superfície da fruta teve $10 \%$ de textura irregular (tangerina 'Ponkan'), 80\% áspera (limão 'Taiti' e 'Branco', nas laranjas 'Lima', 'Seleta Comum', 'Seleta Sanguínea', 'Natal Folha Murcha', 'Pêra Mel' e 'Pêra Rio) e 10\% lisa (laranja 'Bahia'). SARTORI et al. (2002) obtiveram resultados semelhantes para as variedades laranja 'Lima', 'Natal Folha Murcha' e 'Bahia'.

$\mathrm{Na}$ característica polpa da fruta, houve uma variação mediana entre os acessos, 10\% apresentaram a coloração laranja (tangerina 'Ponkan'), 60\% apresentaram coloração amarela (laranja 'Lima', 'Bahia', 'Seleta Comum', 'Natal Folha Murcha', 'Pêra Mel e 'Pêra Rio') 10\% laranja-avermelhado ('Seleta Sanguínea') e $20 \%$ verde (limão 'Taiti' e 'Branco').

As características quantitativas dos frutos também foram avaliadas, em virtude de sua importância para o melhoramento genético e mercado consumidor. As médias das variáveis quantitativas morfoagronômicas de frutos encontram-se disponíveis no Tabela 2.

TABELA 2 - Médias das variáveis morfoagronômicas de frutos de citros coletadas no Setor de Culturas Permanentes do Ifes Campus de Alegre.

Peso do fruto Diâmetro do Comprimento Espessura Espessura 


\begin{tabular}{cccccc}
\hline Variedades & $\mathbf{( g )}$ & fruto $\mathbf{( m m )}$ & do fruto $\mathbf{( m m )}$ & $\begin{array}{c}\text { do } \\
\text { mesocarpo } \\
\text { (mm) }\end{array}$ & $\begin{array}{c}\text { do } \\
\text { epicarpo } \\
\text { (mm) }\end{array}$ \\
\hline $\begin{array}{c}\text { Tangerina } \\
\text { 'Ponkan' }\end{array}$ & $161,95 \pm 1,31$ & $74,29 \pm 1,03$ & $68,86 \pm 1,20$ & $1,15 \pm 1,33$ & $2,25 \pm 0,90$ \\
Limão 'Taiti' & $97,80 \pm 1,21$ & $55,16 \pm 1,32$ & $66,80 \pm 1,01$ & $2,25 \pm 1,07$ & $1,75 \pm 0,35$ \\
Limão 'Branco' & $39,40 \pm 1,02$ & $41,49 \pm 1,38$ & $42,11 \pm 1,21$ & $0,63 \pm 0,56$ & $0,98 \pm 0,30$ \\
Laranja 'Lima' & $130,34 \pm 1,90$ & $64,40 \pm 1,85$ & $61,57 \pm 1,75$ & $3,21 \pm 1,16$ & $2,00 \pm 0,85$ \\
Laranja 'Bahia' & $252,51 \pm 1,00$ & $79,47 \pm 1,10$ & $70,31 \pm 1,23$ & $3,67 \pm 1,34$ & $1,59 \pm 0,99$ \\
$\quad$ 'Seleta & $217,56 \pm 1,30$ & $75,64 \pm 0,91$ & $76,40 \pm 1,69$ & $3,01 \pm 1,18$ & $2,31 \pm 0,76$ \\
$\quad$ Comum' & & & & & \\
$\quad$ 'Seleta & $122,85 \pm 1,53$ & $63,19 \pm 1,30$ & $60,46 \pm 1,84$ & $3,54 \pm 1,00$ & $2,27 \pm 0,94$ \\
Sanguínea' & & & & & \\
'Natal Folha & $179,62 \pm 1,42$ & $69,05 \pm 1,09$ & $72,82 \pm 1,33$ & $2,30 \pm 1,35$ & $1,18 \pm 0,83$ \\
$\quad$ Murcha' & & & & & \\
'Pêra Mel' & $174,37 \pm 1,38$ & $69,22 \pm 1,35$ & $70,25 \pm 1,05$ & $2,59 \pm 1,12$ & $1,15 \pm 0,33$ \\
'Pêra Rio' & $104,85 \pm 1,24$ & $58,54 \pm 1,53$ & $58,52 \pm 1,24$ & $3,34 \pm 1,01$ & $1,54 \pm 0,79$ \\
\hline
\end{tabular}

O peso da fruta variou 39,40g (limão 'Branco') a 252,51g (laranja 'Bahia'). Para o limão 'Taiti' foi obtido 52,37g a 59,45g, PASSOS \& SOARES (2006) afirmam que frutos de limão 'Taiti' com massa média de $50 \mathrm{~g}$ a $70 \mathrm{~g}$ são os preferidos pelo mercado consumidor. Para a laranja, DOMINGUES et al. (2003) descrevem que a preferência do mercado para o consumo in natura é de frutos que possuem peso médio de $150 \mathrm{~g}$, no entanto para SCHWARZ (2011) os frutos que apresentam de $170 \mathrm{~g}$ a $220 \mathrm{~g}$ (massa média) são os preferidos pelo consumidor. Neste contexto, merecem destaque no presente estudo as massas médias obtidas para as variedades 'Pêra Mel', 'Natal Folha Murcha' 'Seleta Comum' (Tabela 2). O diâmetro do fruto variou de 41,49mm (limão 'Branco') a 79,47mm (laranja 'Bahia'). BLUM \& AYUB (2008), encontraram resultados próximos para os valores médios de diâmetro do limão 'Taiti' $(55,16 \mathrm{~mm})$ ao deste trabalho.

O comprimento do fruto variou de $42,1 \mathrm{~mm}$ (limão 'Branco') a 76,40mm (laranja 'Bahia'). O Programa Brasileiro para Modernização da Fruticultura (PBMF, 2013) ressalta que as dimensões satisfatórias para o mercado de frutas frescas do gênero Citrus estão em torno de $70 \mathrm{~mm}$ de comprimento, podendo ser menor que $40 \mathrm{~mm}$ no caso de limões. Conforme os parâmetros citados as variedades, Laranja 'Bahia', 'Seleta Comum', Natal Folha Murcha' e 'Pêra Mel' merecem destaque neste estudo (tabela 2).

A espessura do mesocarpo variou de 0,63mm (limão 'Branco') a 3,67mm (laranja 'Bahia'). Para a espessura do epicarpo houve variação de $0,98 \mathrm{~mm}$ (limão 'Branco') a 2,13mm (laranja 'Seleta Comum'). Segundo CHITARRA \& CHITARRA (2005) durante o amadurecimento dos frutos a espessura da casca diminui e quanto menor esta for maior será o aproveitamento dos frutos para a indústria. De acordo com PASSOS \& SOARES (2006) estas são características desejadas pelos consumidores, para facilitar o descascamento. Destacam-se as variedades de laranja 'Pêra Mel' $(1,15 \mathrm{~mm})$ e 'Natal Folha Murcha' $(1,18 \mathrm{~mm})$.

Constatou-se alta variação para os caracteres físico-químicos estudados. As médias das variáveis físico-químicas dos frutos encontram-se disponíveis na Tabela 3. Foram obtidos valores que atendem aos padrões de qualidade do mercado consumidor de citros, o teor de sólidos solúveis totais em equilíbrio com acidez. 
TABELA 3 - Médias das variáveis físico-químicas de frutos de citros coletadas no Setor de Culturas Permanentes do Ifes Campus de Alegre.

\begin{tabular}{cccccc}
\hline Variedades & Umidade (\%) & Cinzas (\%) & Brix & pH & Acidez (\%) \\
\hline Tangerina 'Ponkan' & $83,60 \pm 0,20$ & $0,87 \pm 0,02$ & 12,86 & 3,12 & $0,97 \pm 0,12$ \\
Limão 'Taiti' & $83,94 \pm 060$ & $0,60 \pm 0,50$ & 7,45 & 2,96 & $5,95 \pm 0,34$ \\
Limão 'Branco' & $79,37 \pm 0,34$ & $0,65 \pm 0,34$ & 6,88 & 3,01 & $5,11 \pm 0,43$ \\
Laranja 'Lima' & $85,22 \pm 0,43$ & $0,99 \pm 0,53$ & 11,21 & 5,98 & $0,23 \pm 0,22$ \\
Laranja 'Bahia' & $83,58 \pm 0,12$ & $0,68 \pm 0,62$ & 12,05 & 3,82 & $0,67 \pm 0,10$ \\
'Seleta Comum' & $87,15 \pm 0,98$ & $0,59 \pm 0,34$ & 10,11 & 3,78 & $0,90 \pm 0,36$ \\
'Seleta Sanguínea' & $81,60 \pm 0,76$ & $0,99 \pm 0,21$ & 11,03 & 3,84 & $0,71 \pm 0,04$ \\
'Natal Folha Murcha' & $82,27 \pm 0,10$ & $1,01 \pm 0,03$ & 11,45 & 4,06 & $0,57 \pm 0,46$ \\
'Pêra Mel' & $84,43 \pm 0,23$ & $0,94 \pm 0,05$ & 11,95 & 3,50 & $0,87 \pm 0,30$ \\
'Pêra Rio' & $82,86 \pm 0,15$ & $1,06 \pm 0,34$ & 11,03 & 3,52 & $0,88 \pm 0,10$ \\
\hline
\end{tabular}

A umidade dos frutos variou de 79,37\% (limão 'Branco') a 87,15\% ('Seleta Comum'). RODRIGUES (2000) encontrou resultados semelhantes, obtendo uma variação de $70 \%$ a $92 \%$. O mesmo autor ressalta que a umidade depende das condições do desenvolvimento da planta e da umidade disponível no solo e no ar.

O teor de cinzas variou de 0,59\% (laranja 'Seleta Comum') a 1,06\% ('Pêra Rio'). DOMINGUES et al. (2003) encontraram resultados semelhantes ao deste trabalho, a variedade 'Seleta Sanguínea' apresentou teores de cinzas de 0,99\%. Segundo FAGUNDES \& YAMANISHI (2005) frutos com maior teor de umidade e menores teores de cinzas apresentam-se mais suculentos e apreciados pelo consumidor (tabela 3).

Os sólidos solúveis totais (SST) tiveram variação entre 6,88Brix (limão 'Branco') e 12,86'Brix (tangerina 'Ponkan'). Levando em consideração que os valores de laranja e tangerina variaram entre 10,11'Brix a 12,86 Brix, o teor de sólidos solúveis foi satisfatório, sendo a tangerina 'Ponkan' e a laranja 'Bahia' as variedades que apresentaram o maior teor de sólidos solúveis.

PEREIRA et al. (2010) descrevem que os teores mínimos de SST, adequados para a colheita de laranjas e tangerinas, devem situar-se em torno de 9,0 a 10,0 Brix. Os sólidos solúveis e a doçura do suco estão diretamente ligados à quantidade de açúcar na fruta, sendo a preferência do mercado consumidor por frutos com teores de açúcares totais superiores a 10ํㅏix (DINIZ \& OLIVEIRA, 2015).

Os sólidos solúveis totais são compostos de todos os constituintes da fruta dissolvidos na porção de água do suco. Segundo NEGREIROS et al. (2014) o teor de sólidos solúveis é usado como indicador de maturidade e também determinam a qualidade do fruto, exercendo importante papel no sabor.

Os valores abaixo de 9,0®rix correspondem às varie dades de limão 'Taiti' e limão 'Branco' que variaram de 6,88Brix a 7,45'Bri $x$, em concordância com os resultados obtidos por Tavares et al. (2004), que encontrou valores $7,5^{\circ}$ Brix para 0 limão 'Taiti'. Os valores de pH variaram de 2,96 (limão 'Taiti') a 5,98 (laranja 'Lima'). PASSOS et al. (2012), trabalhando com limão 'Taiti' observaram valor próximo ao deste estudo ( $\mathrm{pH}$ de 2,77).

$\mathrm{O}$ pH é uma informação bastante relevante para a pesquisa, pois valores de $\mathrm{pH}$ mais baixos colaboram para a conservação do fruto após a colheita, sendo importante característica para o mercado por promover maior durabilidade do fruto. E também tem importância para a indústria de suco, pois seus valores refletem na apreciação e no estado de conservação do produto (NEGREIROS et al., 2014). 
A acidez titulável expressa em porcentagem de ácido cítrico variou entre 0,23 (laranja 'Lima') e 5,95 (limão 'Taiti'), sendo a que laranja 'Lima' a que apresentou o menor teor de acidez. CHITARRA \& CHITARRA (2005), relatam que a acidez, em laranjas e tangerinas, em geral não excede $1 \%$, no caso dos limões ela pode variar de $5,0 \%$ a $7,0 \%$, em concordância com dados deste trabalho. A acidez é o principal parâmetro de qualidade perceptível pelos consumidores e torna-se adequada para o consumo as laranjas e tangerinas que apresentam acidez abaixo de 1,0\% e maior que $0,6 \%$ (POZZAN \& TRIBONI, 2005). Neste caso apenas a variedade laranja 'Lima' e 'Natal Folha Murcha' que não apresentaram teores dentro desses limites.

No comércio de alimentos in natura, pode haver preferência pelas variedades mais doces ou mais ácidas, o que depende do hábito alimentar dos consumidores e dos padrões culturais da região (SPOSITO et al., 2013). Portanto, é necessário disponibilizar ao mercado variedades com diferentes padrões físico-químicos e sensoriais. Nesta pesquisa, as variedades com maior teor de sólidos solúveis foram a tangerina 'Ponkan' e a laranja 'Bahia', enquanto a mais ácida foi o limão 'Taiti' e a menos ácida foi a laranja 'Lima'.

Para análise da diversidade genético-estatística das características qualitativas, a técnica UPGMA foi eficiente no ajuste entre as distâncias, com correlação cofenética de 0,76 para as associações entre a matriz de distância e o dendrograma, já para as variáveis quantitativas a correlação cofenética foi de 0,83 . Estima-se que houve um bom ajuste entre as distâncias, no dendrograma quantitativo, pois de acordo com Sokal e Rohlfe (1995), o ajuste adequado para a diversidade é avaliado pelos valores de correlação cofenética superiores a 0,80 . No dendrograma qualitativo dos dados morfoagronômicos, foram gerados cinco grupos distintos, com ponto de corte na marca 70 (Figura 1).

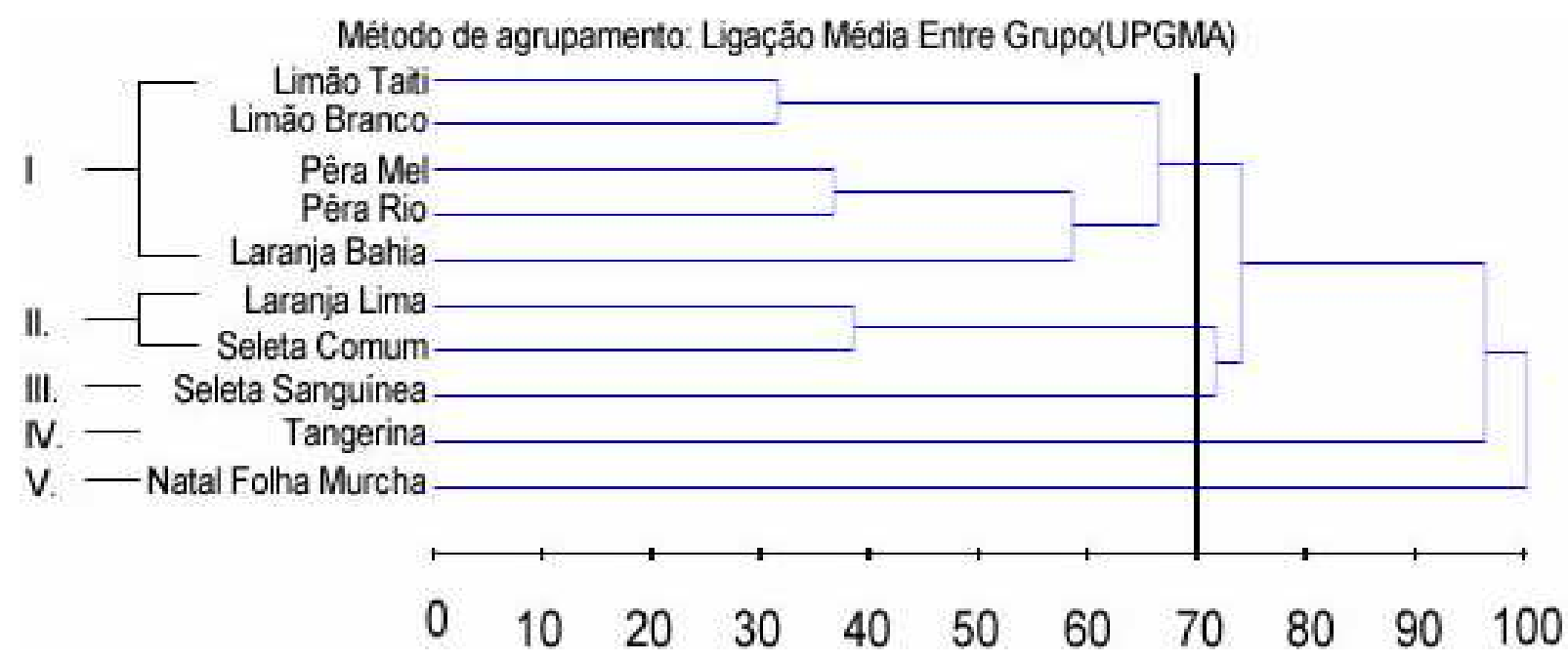

FIGURA 1- Dendrograma qualitativo obtido pelo método UPGMA a partir da matriz de dissimilaridade entre dez variedades de citros coletados no lfes Campus de Alegre.

O grupo I reuniu as variedades de laranja 'Bahia', 'Pêra Rio', 'Pêra Mel', limão 'Taiti' e 'Branco', que são caracterizados por apresentarem o formato do fruto esferoide. O grupo II reuniu as variedades de laranja 'Lima' e 'Seleta Comum' que são caracterizados por apresentarem o formato do fruto elipsoide. O grupo III foi 
formado apenas pela variedade de laranja 'Seleta Sanguínea' por apresentar a coloração laranja-avermelhado.

O grupo IV foi formado apenas pela variedade de tangerina 'Ponkan', a qual apresenta características distintas, a saber: formato da fruta (piriforme), formato da base da fruta (com pescoço), formato do ápice da fruta (depressivo), textura da casca (irregular) cor da polpa (laranja). O grupo $\mathrm{V}$ foi formado apenas pela variedade de laranja 'Natal Folha Murcha' por apresentar o formato da lâmina da folha lanceolado e formato da fruta obliqua.

Para o dendrograma quantitativo (características morfoagronômicas e físicoquímicas) foram gerados quatro grupos distintos, com ponto de corte na marca 25 (Figura 2).

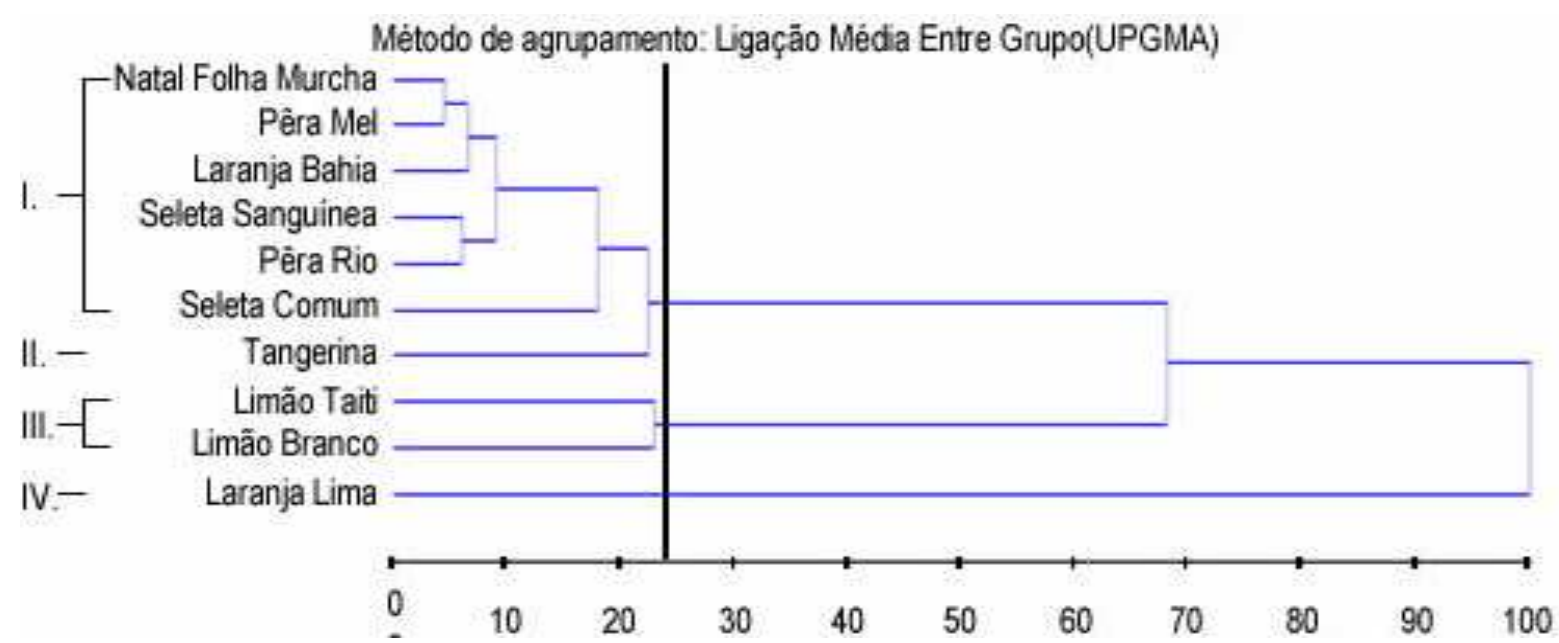

FIGURA 2 - Dendrograma quantitativo obtido pelo método UPGMA a partir da matriz de dissimilaridade entre dez acessos de citros coletados no Ifes Campus de Alegre.

O grupo I reuniu as variedades de laranja 'Pêra Mel', 'Natal Folha Murcha', 'Bahia', 'Seleta Comum', 'Seleta Sanguínea' e 'Pêra Rio' que são caracterizados por apresentarem valores de $\mathrm{pH}$ medianos e diâmetros maiores. O grupo II foi constituído apenas pela tangerina 'Ponkan' por apresentar maior valor de ${ }^{\circ}$ Brix $(12,86)$. O grupo III reuniu as variedades de limão 'Taiti' e 'Branco' por apresentarem maior teor de acidez, menor $\mathrm{pH}$, menor comprimento e diâmetro do fruto. $\mathrm{E}$ o grupo IV foi formado pela laranja 'Lima' por apresentar maior pH e menor acidez.

O dendrograma quantitativo agrupou as variedades de forma satisfatória, o que comprovou a eficácia das mensurações de características de herança quantitativa ou polimérica em comparação com a herança qualitativa. Pode-se constatar que o grupo I foi constituído pelas laranjas (exceto laranja 'Lima'), o grupo II pela tangerina 'Ponkan', o grupo III pelos limões e o grupo IV pela laranja 'Lima', o que ressalta a real proximidade das variedades dentro de cada grupo e caracteriza de forma discriminativa as variedades de citros mantidas no Ifes Campus de Alegre.

Por intermédio da medida de dissimilaridade entre os pares de acessos, expressa pela distância generalizada de Mahalanobis, no dendrograma qualitativo, foi verificado que os genótipos mais divergentes, ou seja, os que possuem maior diversidade entre os acessos, são a tangerina 'Ponkan' e a laranja 'Natal Folha Murcha',com uma distância de quase 0,98. Enquanto as variedades limão 'Taiti' e 'Branco' foram consideradas as mais próximas geneticamente, com uma distância de 0,30 . 
Já no dendrograma quantitativo foi verificado que o genótipo mais distante foi a laranja 'Lima' com uma distância de quase 0,99. Os acessos mais próximos foram as laranjas 'Natal Folha Murcha' e a 'Pêra Mel', com uma distância de 0,32, isso se deve aos resultados semelhantes com valores físico-químicos, largura e espessura da folha, e comprimento, diâmetro e peso do fruto. A distância entre os acessos estudados neste trabalho indica uma diversidade considerável entre os genótipos no que diz respeito às características qualitativas e quantitativas avaliadas.

\section{CONCLUSÕES}

Foi observada alta variabilidade fenotípica entre as variedades coletadas, com diferentes formatos, tamanhos e cores. A caracterização morfoagronômica e físicoquímica foram eficientes para evidenciar divergência entre os genótipos, sendo importante ferramenta para o conhecimento e uso das variedades de citros do Ifes Campus de Alegre.

As características quantitativas mensuradas possibilitaram um melhor agrupamento das variedades de citros do Ifes Campus de Alegre, havendo separação satisfatória das laranjas, limões e tangerina.

\section{REFERÊNCIAS}

ARAÚJO A. R. G.; SALIBE, A. A. Caracterização físico-morfológica de frutos de microtangerinas (Citrus spp.) de potencial utilização como porta-enxertos. Revista Brasileira de Fruticultura, Jaboticabal, v. 24, n. 3, p. 618-621, 2002. Disponível em: <http://www.scielo.br/scielo.php?pid=S010029452002000300009\&script=sci_abstract \&tlng=pt>. DOI: 10.1590/S0100-29452002000300009.

BLUM, J.; AYUB, R. A. Conservação pós-colheita da lima ácida "Tahiti” tratada com 1-metilciclopropeno. Revista Biotemas, v. 21, n. 2, p. 27-31, 2008. Disponível em: < https://periodicos.ufsc.br/index.php/biotemas/article/view/20852>. 10.5007/2175-7925.

CHITARRA, M. I. F.; CHITARRA, A. B. Pós-colheita de frutas e hortaliças: fisiologia e manuseio. 2. ed. rev. ampliada e atual. Lavras: UFLA, 2005.

CRUZ, C.D. Programa genes (versão Windows): aplicativo computacional em genética e estatística. Viçosa: UFV. 2008.

DAWYNDT, P.; HANS, M.; BERNARD, B. UPGMA clustering revisited: A weightdriven approach to transitive approximation. International Journal of Approximate Reasoning v. 42, n. 3, p. 174-191, 2006. Disponível em: http://www.sciencedirect.com/science/article/pii/S0888613X05000940. DOI: 10.1016/j.ijar.2005.11.001.

FAGUNDES, G. R.; YAMANISHI, O. K. Melhoramento genético de citros. 1. Ed. Guanabara, 2014.

IAL. Instituto Adolfo Lutz. Normas analíticas do Instituto Adolfo Lutz. São Paulo, 1976. v.1. 371p.

IBPGR. International board for plant genetic resources. Descriptors for Citrus. Rome, 1988. 27p. 
LIMA, J. S. S.; SILVA, S. A.; OLIVEIRA, R. B.; CECÍLIO, R. A.; XAVIER, A. C. Variabilidade temporal da precipitação mensal em Alegre-ES. Revista Ciência Agronômica, Fortaleza, v. 39, n. 2, p.327-332, 2008. Disponível em: <http://ccarevista.ufc.br/seer/index.php/ccarevista/article/view/67>. $\quad$ DOI: $10.1590 / \mathrm{S} 0102-77862011000400013$

MEDEIROS, R. C.; MUSSER, R. D. S.; SILVA, M. M. D.; SANTOS, J. P. O.; NASCIMENTO-JÚNIOR, I. R. D. Exploratory analysis of morphological and qualitative characteristics of orange varieties in brejão-ep collection. Revista Brasileira de Fruticultura, v. 35, n. 2, p. 500-507, 2013. Disponível em: < http://www.scielo.br/scielo.php?pid=S0100-29452013000200020\&script=sci_arttext>. DOI: 10.1590/S0100-29452013000200020.

NEGREIROS, J. R. D. S., ANDRADE-NETO, R. D. C., MIQUELONI, D. P., \& LESSA, L. S. Estimativa de repetibilidade para caracteres de qualidade de frutos de laranjeira-doce. Pesquisa Agropecuária Brasileira, v. 49, p. 40-48, 2014. Disponível em: < http://www.scielo.br/pdf/pab/v49n1/0100-204X-pab-49-0100040.pdf>. DOI: 10.1590/S0100-204X2014000100006.

OLIVEIRA, R. P., SOARES FILHO, W. S., PASSOS, O. S., SCIVITTARO, W. B., ROCHA, P. S. G. Laranja Lima (Citrus sinensis) -Documentos , 226. Embrapa Clima Temperado, Pelotas -RS, 45 p, 2008.

PAIVA, R.; OLIVEIRA, L.M. Fisiologia e produção vegetal de laranja Bahia. Lavras: UFLA, 2006. 104p.

PASSOS, O.S; CUNHA, S. A. P. C.; SOARES-FILHO, W. S. S Lima ácida 'Tahiti': uma alternativa para a citricultura do nordeste Brasileiro. Cruz das Almas, Embrapa Mandioca e Fruticultura. 20p. (Documentos, 101), 2012.

PASSOS, O. S.; SOARES FILHO, W. S. Alternativas de porta-enxerto de citros no Nordeste do Brasil. Embrapa Mandioca e fruticultura tropical, dezembro de 2005 (folder). aput: POMPEU JÚNIOR. J. e BLUMER,S., Laranja, Cordenópolis, v. 27 , n. 2 p.341-354, 2006.

PEREIRA; M. E. C.; CANTILLANO F. F.; GUTIEREZ, A. S. D. ALMEIDA G. V. B. Procedimentos pós-colheita na produção integrada de citros. Cruz das almas: Embrapa Mandioca e Fruticultura Tropical, 2010. p. 40. (Documentos, 156).

PIMENTEL, C. V. M. B.; FRANCKI, V. M.; GOLLÜCKE, A. P. B. Alimentos funcionais: introdução as principais substâncias bioativas em alimentos. São Paulo: Ed. Varela, 2013. 95 p.

PBMF. PROGRAMA BRASILEIRO PARA MODERNIZAÇÃO DA FRUTICULTURA. Normas de classificação de citros de mesa. São Paulo: CEAGESP, 2013. p.12.

SARTORI, I. A. Maturação de frutos de seis cultivares de laranjas-doces na depressão central do Rio Grande do Sul. Revista Brasileira de Fruticultura, v. 24, n. 2, p. 364-369, 2012. Disponível em: < http://www.scielo.br/scielo.php?pid=S0100- 
29452002000200018.

SCHWARZ, S. F. Melhoramento genético e variedades. In: KOLLER, O. C. (Org.). Citricultura: 1. Laranja: tecnologia de produção, pós-colheita, industrialização e comercialização. $2^{\circ}$ ed. Porto Alegre: Cinco Contine ntes, 2011. p. 9-18.

SIRGAS: O Sistema de Referência para o novo milênio. I SEMINÁRIO SOBRE REFERENCIAL GEOCÊNTRICO NO BRASIL, 2000.

SOKAL, R.R.; ROHLFE, F.J. Biometry: The principles and practice of statistics in biological research. WH Freeman and Company. New York, USA. 3ª edição. 1995.

SPOSITO, M. B.; MOURAO FILHO, F. de A. A.; KLUGE, R. A.; JACOMINO, A. P. Caracterização fisico-quimica de citros no nordeste. 1 ed. Jaboticabal-SP, 2013.

STENZEL, N. M. C. Comportamento da laranjeira Folha Murcha em sete portaenxertos no Noroeste do Paraná. Revista Brasileira de Fruticultura, v. 27, n. 3, p.408-411, 2011. Disponível em: < http://www.scielo.br/pdf/\%0D/rbf/v27n3/27785.pdf>. $\quad$ DOI: $\quad 10.1590 / S 0100-$ 29452005000300017.

OLIVEIRA, D. R.; DINIZ, A. B. Composição química da laranja kinkan e de frutas cítricas. DEMETRA: Alimentação, Nutrição \& Saúde, v. 1, p. 835-844, 2015. Disponível em: http://www.epublicacoes.uerj.br/index.php/demetra/article/view/16726\#.Vu6RnxHmrml. DOI: 10.12957/demetra.2015.16726.

TODISCO, K. M.; CLEMENTE, E.; ROSA, C. I. L. F. Conservação e qualidade póscolheita de laranjas „Folha Murcha $\square$ armazenadas em duas temperaturas. Revista em Agronegócio e Meio Ambiente, Maringá, v. 5, n. 3, p. 579-591, set./dez. 2012. Disponível em:

http://periodicos.unicesumar.edu.br/index.php/rama/article/view/2102> 10.3738/1982.2278.981.

ZULIAN, A., DÖRR, A. C.; ALMEIDA, S. C. Citricultura e agronegócio cooperativo no Brasil. Revista Eletrônica em Gestão, Educação e Tecnologia Ambiental, v. 11, p. 2291-2306, 2013. Disponível em: < http://cascavel.ufsm.br/revistas/ojs2.2.2/index.php/reget/article/view/8700 >. DOI: 10.5902/22361170. 